Editorial

\title{
High Performance Concrete Materials with Applications in Building and Civil Engineering
}

\author{
Peng Zhang, ${ }^{1}$ Song Han, ${ }^{2}$ Serina $\mathrm{Ng}^{3}$ and Xu-Hao Wang ${ }^{4}$ \\ ${ }^{1}$ School of Water Conservancy and Environment Engineering, Zhengzhou University, Zhengzhou 450001, China \\ ${ }^{2}$ School of Civil Engineering, Beijing Jiaotong University, Beijing 100044, China \\ ${ }^{3}$ Department of Materials and Structures, SINTEF Building and Infrastructure, 7465 Trondheim, Norway \\ ${ }^{4}$ National Concrete Pavement Technology Center, Iowa State University, Ames, IA 50011, USA
}

Correspondence should be addressed to Peng Zhang; zhangpeng@zzu.edu.cn

Received 9 March 2017; Accepted 20 March 2017; Published 19 April 2017

Copyright (C) 2017 Peng Zhang et al. This is an open access article distributed under the Creative Commons Attribution License, which permits unrestricted use, distribution, and reproduction in any medium, provided the original work is properly cited.

Concrete materials are the most widely used and most consumable building material in the world and have grown tremendously in recent years due to the high strength, high elasticity modulus, well plasticity, and workability. The development tendency of the modern civil engineering structures is high strength, high rise, and long design lifetime, which has higher requirements on concrete. High performance concrete can be defined as the concrete that can meet special combinations of properties and uniformity requirements, which can not always be achieved routinely using traditional raw materials and conventional mixing, placing, and curing methods [1]. The development of high performance concrete materials, especially the ultra high performance concrete, will provide better materials for specific projects in civil engineering. Compared with the traditional concrete, high performance concrete materials have more excellent mechanical properties and durability, and the use of them in civil engineering is becoming more and more wide [2]. A large number of researchers are targeting developments of high performance concrete and also working on the mechanism research for special properties, preparation technology, testing methods, modeling, and applications of various high performance building materials. Generally, there are many ways to get high performance concrete. Usually, special aggregates, binding materials, and admixtures can be added to the traditional concrete to obtain high performance concrete. For example, some unconventional aggregates [3], mineral admixtures [4], chemical admixtures [5], and different fibers [6] can be used to produce high performance concrete.

This special issue aims to bring researchers from academia and industry together to report and explore the new preparation methods, new investigations techniques, material properties, and applications in high performance concrete materials and review the latest progress in this field. Out of about seventeen submissions, eight research manuscripts have been selected and included in this special issue because of their good quality and relevance to the theme. The selected articles address various aspects, including an improved micromechanical framework with interfacial transition zone (ITZ) for saturated concrete repaired by the electrochemical deposition method, bending and shear properties of composite slabs made up of lightweight concrete, transport properties of high performance concrete based on AC impedance spectroscopy techniques, flexural properties of steel fiber cementitious composite externally reinforced with basalt FRP sheet, transport properties of near-surface concrete, a model of mechanical properties of nanomaterials reinforced cementitious composites, hysteresis properties and a restoring force model for corroded reinforced concrete frame columns, and mechanical properties of high performance concrete containing metakaolin and polymer admixture.

The paper titled "An Improved Micromechanical Framework for Saturated Concrete Repaired by the Electrochemical Deposition Method Considering the Imperfect Bonding" is 
authored by Q. Chen et al. They provided an improved micromechanical framework with interfacial transition zone in order to explain the deposition healing process with micromechanics for saturated concrete. To predict the effective performance of repaired concrete taking the interfacial transition zone effect into account, the new multilevel homogenization schemes were adopted. They also proposed the modification process in reaching the high performance of repaired concrete under dry condition. The comparison of the prediction results gained from the improved model provided in this paper and the results gained from other current models have been carried out to illustrate the reasonability of the improved micromechanical model. Furthermore, the authors discussed the effects of the deposition product and interfacial transition zone on the effectiveness of healing.

The paper titled "Bending and Shear Experimental Tests and Numerical Analysis of Composite Slabs Made Up of Lightweight Concrete" is authored by F. P. A. Rabanal et al. Through a series of $\mathrm{m}-\mathrm{k}$ experiments with advanced techniques and the numerical simulations on flexural properties of composite slabs with two lengths, which are made of three kinds of lightweight concrete and steel, they investigated the structural strengths of the composite slabs. Based on the test results, the dimensionless coefficients were obtained to compare the effect of different sizes of the slabs on the structural performance. Moreover, the finite element methods were used to perform the nonlinear numerical simulations applying four various multilinear isotropic hardening laws. The friction coefficient between the concrete and steel was modeled using coulomb friction contact. The results indicate that the numerical results are very consistent with the results of the experiments; as a result the numerical models established in this paper can be applied in improving and optimizing the composite slabs produced with lightweight concrete.

The paper titled "Determination of the Transport Properties of Structural Concrete Using AC Impedance Spectroscopy Techniques" is authored by $\mathrm{L}$. Wu et al. They measured the chloride ion diffusion coefficient of high performance concrete using AC impedance spectroscopy technology to investigate the transport performance of high performance concrete. By adopting the equivalent circuit model, they also deduced the relationship between the chloride ion diffusion coefficient and mesostructure parameters and proposed a diffusion coefficient determining measure using AC impedance spectroscopy technique. The results showed that the chloride ion diffusion coefficient could be amended when considering the conductivity difference resulting by different cementitious materials. The comparison of ASTM C1202 method and the method presented in this paper indicated that there is a linear correlation between the two methods due to the fact that the method of ASTM C1202 is affected by the pore solution conductivity, which has small influence on the chloride ion diffusion performance of the concrete compared to the interconnected porosity.

S. Kim and C. Park conducted a study on the flexural properties of basalt FRP externally reinforced high performance cementitious composites containing steel fibers with the volume content of $8 \%$. Their paper is titled "Flexural
Behavior of High-Volume Steel Fiber Cementitious Composite Externally Reinforced with Basalt FRP Sheet.” Based on the study results, it is noted that the best reinforcement method of the basalt fiber sheet to the beam structures among the methods mentioned in this paper is single-layered $45^{\circ}$ oriented method, and the maximum load ratio can not be increased consequentially with the increase of the layers and thickness of BFRP materials. It can also be concluded that the toughness and strength of the beam could be increasing with the increase of the ductility of the constraint.

$\mathrm{L}$. Wu et al. presented an appropriate method to determine chloride ion diffusion coefficient suitable for in situ, which was based on the relationship between the chloride ion diffusion coefficient and the alternating current impedance spectroscopy parameters. Their paper is titled "In Situ Determination of the Transport Properties of Near-Surface Concrete Using AC Impedance Spectroscopy Techniques." The proposed method well reflects the transport performance of the near-surface concrete and the reinforcing bar will not have any effect on this method. Their experiment results indicate that the new method is exactly consistent with "PERMIT" migration test and it can save more measuring time compared to the traditional method.

The paper titled "Model of the Mechanical Behavior of Cementitious Matrices Reinforced with Nanomaterials" is authored by V. D. Balopoulos et al. They developed a mechanistic computational model to assess the restriction function of the nanoparticles to reinforce the gel microstructure under the common stress state. In order to assess the influence of the reinforcement of the nanomaterials on the phenomenological performance of the composites, the composites were investigated under different common stress states applying the model proposed. The application results show that the modeling process chosen in this study can successfully copy the known tendency in mechanical performance of cementitious composites, which covers the sensitivity of the yield and failure stress to the transverse restriction and the ratio of uniaxial tensile and compression strength.

G. Zhao et al. conducted a numerical simulation of the hysteresis properties of corroded reinforced concrete frame columns. Their paper is titled "The Hysteresis Performance and Restoring Force Model for Corroded Reinforced Concrete Frame Columns." Based on the numerical simulation, the authors established a retrogressive three-linearity restoring force model, which well reflected the hysteresis properties of corroded reinforced concrete frame columns. The analysis indicates that the hysteretic bearing capacity of the frame columns greatly reduces because of the corrosion of the steel rebar. From the hysteresis curves obtained by the model established in this study, it can be concluded that there is similar characters to those of the experimental curves, which proves that the restoring force model founded in this study is accurate, rational, applicable, and simple in usage.

The paper titled "The Mechanical Properties of the Concrete Using Metakaolin Additive and Polymer Admixture" is authored by A. Al Menhosh et al. They reported the influence of the blended addition of polymer and metakaolin on the durability and the mechanical performance of high 
performance concrete. In their investigation, various dosages of metakaolin, polymers, and recycled fibers were used as the combinations. Moreover, the influence of curing methods and water to cement ratio on mechanical performance was revealed, and the optimal mix proportion was suggested based on the experiments. The results indicate that the addition of metakaolin can accelerate the setting time of concrete but reduce the flowability of fresh concrete, and the inclusion of plastic and glass fibers obviously enhances the tensile strength of the concrete. The combination of $15 \%$ metakaolin and $5 \%$ optimal polymer can produce the concrete exhibiting wonderful strength and durability.

\section{Acknowledgments}

We would like to thank the authors who have submitted manuscripts to this special issue. We would also like to acknowledge the referees who have put in the hard work and their valuable time to review each paper in a timely and professional way. The lead editor thanks all the editors for their contribution in reviewing and assigning reviews for the submitted manuscripts.

$$
\begin{array}{r}
\text { Peng Zhang } \\
\text { Song Han } \\
\text { Serina Ng } \\
\text { Xu-Hao Wang }
\end{array}
$$

\section{References}

[1] B. J. Olawuyi and W. P. Boshoff, "Influence of SAP content and curing age on air void distribution of high performance concrete using 3D volume analysis," Construction and Building Materials, vol. 135, pp. 580-589, 2017.

[2] P. Zhang, C. Liu, and Q. Li, "Application of gray relational analysis for chloride permeability and freeze-thaw resistance of high-performance concrete containing nanoparticles," Journal of Materials in Civil Engineering, vol. 23, no. 12, pp. 1760-1763, 2011.

[3] N. Flores Medina, D. Flores-Medina, and F. HernándezOlivares, "Influence of fibers partially coated with rubber from tire recycling as aggregate on the acoustical properties of rubberized concrete," Construction and Building Materials, vol. 129, pp. 25-36, 2016.

[4] P. Zhang, Q.-Y. Guan, C.-H. Liu, and Q.-F. Li, "Study on notch sensitivity of fracture properties of concrete containing nano$\mathrm{SiO}_{2}$ particles and fly ash," Journal of Nanomaterials, vol. 2013, Article ID 381682, 7 pages, 2013.

[5] R. Zhang, Q. Wang, L. Ma, Y. Yang, and L. Qi, "Effect of interaction between expanding agent proportion and stress ratio on creep characteristics of concrete filed steel tube," Journal of Central South University (Science and Technology), vol. 45, no. 7, pp. 2416-2423, 2014.

[6] P. Zhang and Q.-F. Li, "Effect of polypropylene fiber on durability of concrete composite containing fly ash and silica fume," Composites Part B: Engineering, vol. 45, no. 1, pp. 1587-1594, 2013. 


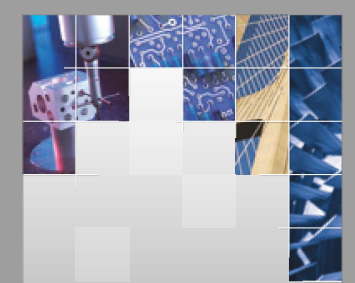

\section{Enfincering}
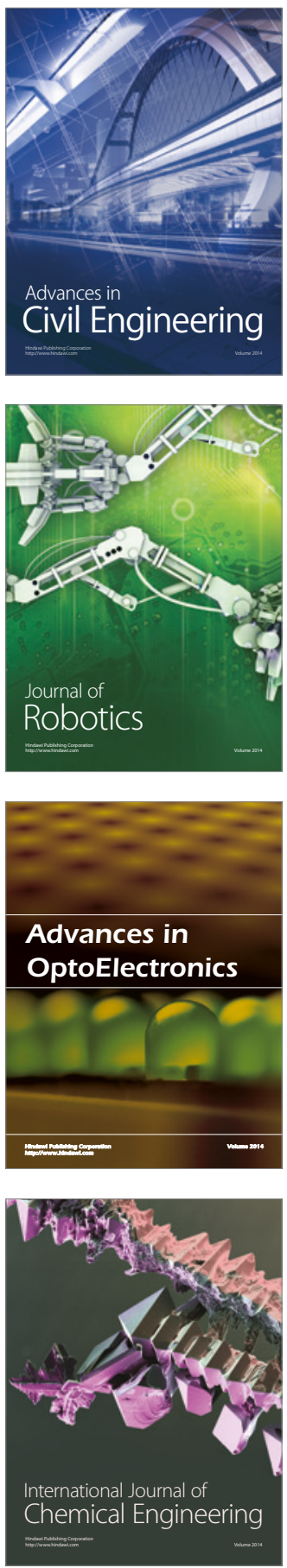

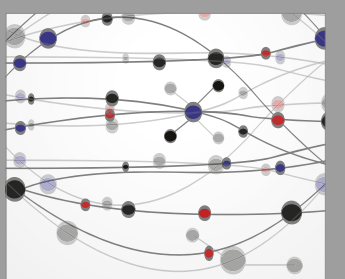

The Scientific World Journal

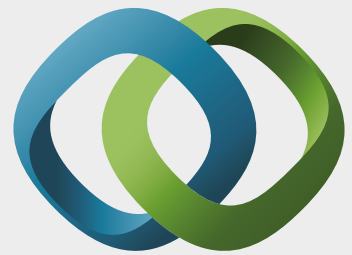

\section{Hindawi}

Submit your manuscripts at

https://www.hindawi.com
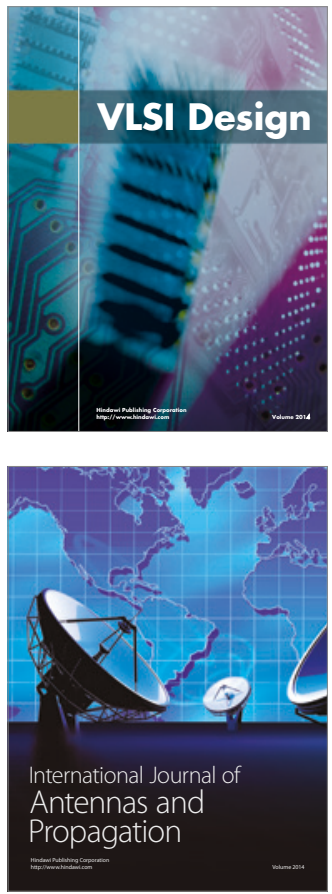

\section{Rotating}

Machinery
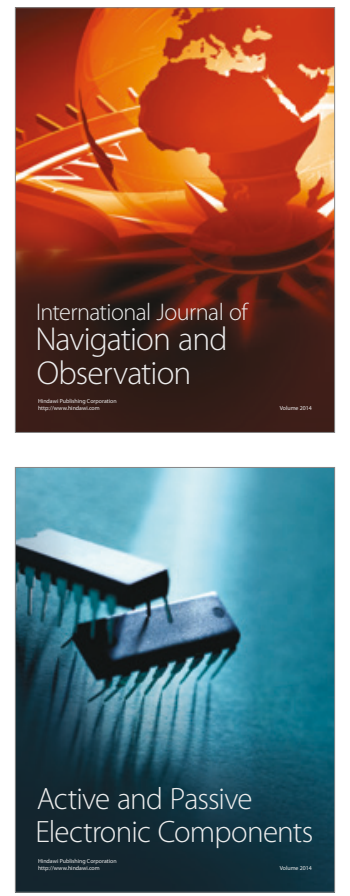
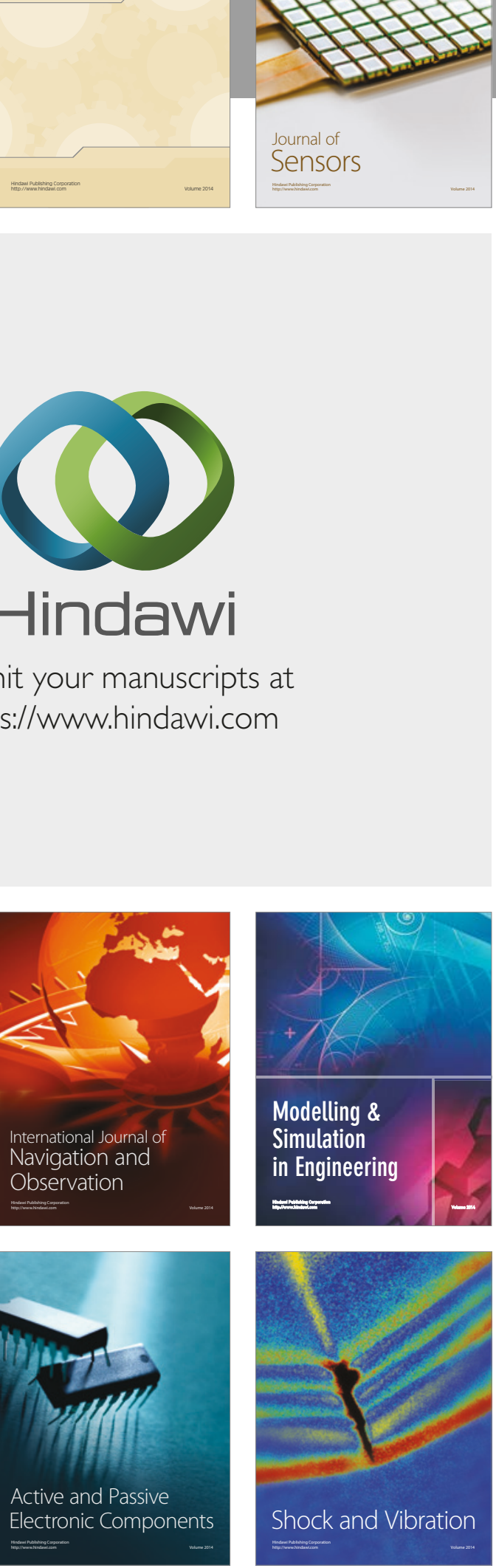
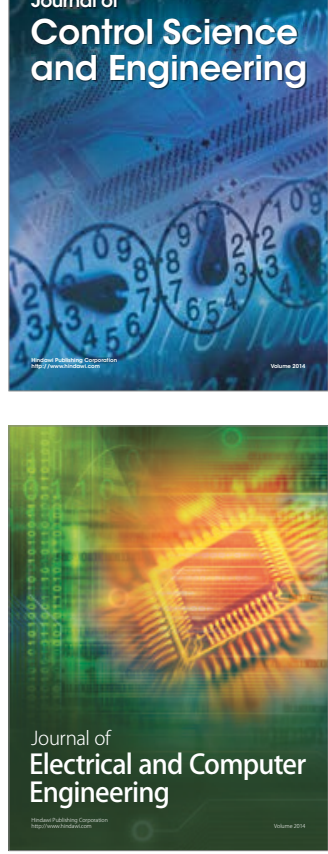

Distributed

Journal of

Control Science

and Engineering
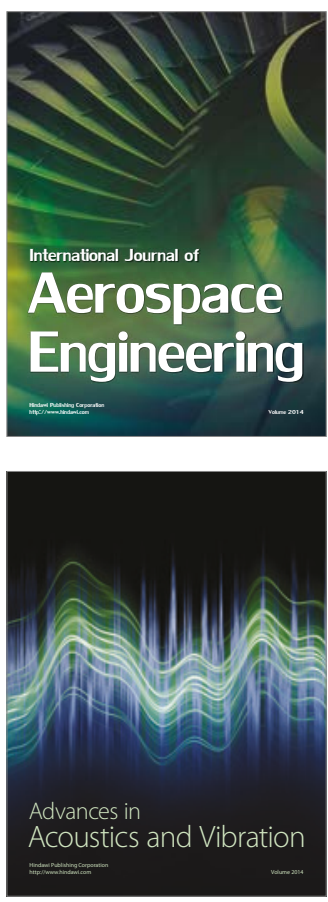

Sensor Networks 